\title{
Immune Response Scenario and Vaccine Development during COVID-19 Infection
}

\author{
Mai Mohammad ${ }^{1}$ \\ ${ }^{1}$ Suez Canal University Faculty of Medicine
}

September 11, 2020

\begin{abstract}
COVID-19 pandemic has started in December 2019 in China and quickly extended to become a worldwide health and economic emergency issue. It is caused by the novel coronavirus; SARS-CoV-2. COVID-19 patients' clinical presentations vary from asymptomatic infection or flu like symptoms to serious pneumonia which could be associated with multiple organ failure possibly leading to death. It is understood that the immune response to SARS-CoV-2 includes all elements of the immune system which could altogether succeed in viral elimination and complete cure. Meanwhile, this immune response may also lead to progression of disease and could be responsible for the patient's death. Many trials have been done recently to create therapies and vaccines against human coronavirus infections such as MERS or SARS, however, till now, no effective antiviral drugs or vaccines have been approved to treat or prevent this disease and its management depends mainly on supportive care. The spike glycoprotein or protein S of SARS-CoV-2 is the main promoter that induces development of neutralizing antibodies; hence, many attempts of vaccines and antiviral drugs development have been designed to be directed specifically against this protein. While some of these attempts have been proved to be efficient in in vitro settings, only few of them have been proceeded to randomized animal trials and human studies which makes Covid-19 prevention an ongoing challenge. This review describes the natural immune response scenario during COVID-19 and the vaccines development trials to create efficient vaccines thus helping to build more effective approaches for prophylaxis and management.
\end{abstract}

\begin{abstract}
:
COVID-19 pandemic has started in December 2019 in China and quickly extended to become a worldwide health and economic emergency issue. It is caused by the novel coronavirus; SARS-CoV-2. COVID-19 patients' clinical presentations vary from asymptomatic infection or flu like symptoms to serious pneumonia which could be associated with multiple organ failure possibly leading to death. It is understood that the immune response to SARS-CoV-2 includes all elements of the immune system which could altogether succeed in viral elimination and complete cure. Meanwhile, this immune response may also lead to progression of disease and could be responsible for the patient's death. Many trials have been done recently to create therapies and vaccines against human coronavirus infections such as MERS or SARS, however, till now, no effective antiviral drugs or vaccines have been approved to treat or prevent this disease and its management depends mainly on supportive care. The spike glycoprotein or protein S of SARS-CoV-2 is the main promoter that induces development of neutralizing antibodies; hence, many attempts of vaccines and antiviral drugs development have been designed to be directed specifically against this protein. While some of these attempts have been proved to be efficient in in vitro settings, only few of them have been proceeded to randomized animal trials and human studies which makes Covid-19 prevention an ongoing challenge.
\end{abstract}

This review describes the natural immune response scenario during COVID-19 and the vaccines development trials to create efficient vaccines thus helping to build more effective approaches for prophylaxis and management. 
Keywords: Novel coronavirus, COVID-19, SARS COV-2, immune response, cytokine storm, vaccines

\section{Introduction:}

COVID-19 was announced as a pandemic on March 11, 2020 with more than 23 million confirmed cases and 809.484 reported deaths all over the world by August 24, 2020(1). The origin of this viral infection was in Wuhan city, Hubei province, China, where a series of cases were first discovered in December 2019 (2).

The etiology was immediately determined as beta coronavirus with high sequence homology to bat coronaviruses (CoVs) which uses the angiotensin-converting enzyme 2 (ACE2) receptor as the main cell entry process(3). Its human to human transmission was confirmed following possible zoonotic spillover. SARSCoV-2 is also closely linked to SARS (previously named SARS-CoV-1) and Middle Eastern Respiratory Syndrome (MERS) CoVs, which resulted in zoonotic and local outbreaks in 2003 and 2012, respectively. Covid-19 patients present clinically with wide range of symptoms varying from no or mild symptoms like influenza clinical picture to more severe forms of pyrexia, cough, dyspnea, sometimes followed by respiratory failure and multi system failure then death(4). Whereas SARS-CoV-2 is less deadly than SARS or MERS; its lethality rate is estimated to be $2.7 \%$ versus $9.6 \%$ for SARS and $35 \%$ for MERS(5), however its global extension has led to immense uncertainty and devastating effects in many countries due to its high infectivity rate requiring specialized medical care in intensive care units (ICU) (6) and revealing the unseen vulnerabilities of health systems and the importance of global health cooperation.

The most seriously affected population is the old age group, especially those suffering from chronic diseases as well as the immunocompromised patients. Additionally, there are some regional differences in Covid-19 infection patterns whose causes are not clearly understood $(7)$.

Although a fast and coordinated immune response exerts the first line of defense in Covid-19, exaggerated production of inflammatory cytokines during the innate response could result in tissue injury either at the site of infection or systemically. Moreover, a dysregulated cell mediated and humoral response may worsen the condition. It was reported that significant changes occur in both the innate and adaptive immune response while encountering SARS-CoV-2 leading to enormous release of cytokines or the "cytokine storm" which represents the ongoing hysterical activation of the immune system(8).

There is no fully effective therapy till now particularly for the less immunocompetent patients which makes evading complications a real challenge. Most of the suggested therapies for Covid-19 are derived from those used previously in treatment of related viruses such as SARS and MERS or other viruses as Zika or Ebola. Examples of treatments that showed some success till now are remdesivir (adenosine analogue), lopinavir/ritonavir (protease inhibitors) alone or combined with interferon- $\beta$, chloroquine, hydroxychloroquine and plasma therapy $(9)$.

The diminished commercial production of effective therapies and vaccines for Covid-19 and related Corona viruses could be in part due to decreased interest of the pharmaceutical corporations. Usually, during epidemics, the requirement for developing a therapeutic drug or a vaccine lasts only for short period which is the stay of the infection as there might be no patients available for clinical trials by the time the new therapy is produced(10).

Since there is limited control of the pandemic even by physical distancing and good hygiene measurements and there is minimal understanding of the cytokine storm nature and the changes that occur in the signaling pathways stimulated by SARS-CoV-2, thus, better identification of the immune response scenario in Covid19 patients especially at the molecular level could help finding the molecular targets either for therapy or vaccines.

The aim of this review is to focus on the main aspects of both the innate and adaptive immune responses as well as the effective vaccines strategies for SARS-CoV-2.

\section{Virology:}


The virus was identified by $\mathrm{Wu}$ et al.(11) and named it WH-Human 1, and by Zhou et al., simultaneously, who named it 2019-nCoV (12). Later on, the virus name was changed to "SARS-CoV-2" by the Coronavirus Study Group (CSG) of International Committee on Taxonomy of Viruses (ICTV), since it was found to be the sister virus of severe acute respiratory syndrome coronavirus (SARS-CoV)(13). Based on this, the WHO officially announced the virus name as SARS-CoV-2 and the infection as Covid-19 by February 11, 2020 (14).

Coronaviruses belong to the family Coronaviridae (subfamily Coronavirinae) and are capable of infecting various wild animals as well as humans where they can cause diseases ranging from mild flu to severe respiratory infections and sometimes fatal complications (13). Among the $6 \mathrm{CoVs}$ which are pathogenic to humans, 4 of them have led to mild respiratory infections, however, the other 2 viruses; SARS and the Middle East respiratory syndrome (MERS) were responsible for epidemics of severe respiratory infections in 2003 and 2012 respectively(15). SARS and MERS have a lower infectivity rate but a higher lethality than SARS-CoV-2 which showed tremendously higher infectivity with apparently lower lethality rate(16).

SARS-CoV-2 is the 7th identified Corona virus and the 3rd zoonotic virus of CoVs that has been transmitted from animals to humans after SARS and MERS (17),(18). In fact, the Chinese horseshoe bats have been proposed to serve as the primary source for SARS-CoV-2. It was reported that SARS-CoV-2 genome has shown around $80 \%$ similarity with SARS (19) and nearly all its encoded proteins are homologous with those of $\operatorname{SARS}(8)$.

Corona viruses are enveloped single stranded positive sense RNA viruses; their RNA is approximately 30 Kbp. They have a spheroidal shape, their diameter is $80-120 \mathrm{~nm}$ and their envelope holds the structural proteins; spike (S), membrane (M), and envelope (E), and they include the nucleocapsid $(\mathrm{N})$ inside the virion which covers the RNA(20).

$\mathrm{S}$ is a glycoprotein that projects from the viral membrane, giving it the crown shape and hence the corona virus name, it also helps in the attachment of the virus to different surfaces leading to its high stability and infectivity. Glycoprotein S is composed of 2 subunits: S1 which contains the receptor binding domain (RBD) and also has epitopes that could be recognized by $\mathrm{T}$ and $\mathrm{B}$ lymphocytes and induce the production of neutralizing antibodies; and S2 which induces the fusion of the virion with the host cell membrane (16).

The surface angiotensin-converting enzyme 2 (ACE2), which is expressed on type-I and -II alveolar cells of the lungs is the main receptor that allows the entrance of SARS-CoV-2 into human host cells. Noteworthy, the expression of ACE2 receptors is not only restricted to the lung cells but their expression on small intestine enterocytes, kidney proximal tubules cells, endothelial cells of arteries and veins, and the arterial smooth muscle was also demonstrated which may explain the extrapulmonary spread of SARS-CoV-2(21). Furthermore, homology modeling showed great degree of structural resemblance between the receptor-binding domains of SARS and SARS-CoV-2(22). However, the degree of affinity of the 2 viruses to their receptors may vary which may be the cause of the higher infectivity and virulence of SARS-CoV-2 in comparison to SARS (23).

Binding between RBD of the virus and its receptor initiates conformational changes of S protein which causes cleavage of S1 and S2 which is a fundamental step that enables S2 to induce the fusion of the virus envelope with the cell membrane followed by the internalization of the viral RNA into the cytoplasm of the host cells by endocytosis(20), (24). Next, the viral RNA acts as a template for the translation of the polyproteins pp1a and pp1b which are then cleaved into 5- 16 non-structural proteins (nsp2-nsp9), which in turn induce reorganization of the membranes to form the vesicles where viral replication and transcription complexes are formed then the assembly of the virions starts and the mature virions are released from the cells by the secretory pathway to infect the neighboring cells (20).

In addition, it was found that entry of the virus in helped by the cellular host type 2 transmembrane serine protease (TMPRSS2) which is expressed on many cell types and has a role in priming the $\mathrm{S}$ protein leading to its cleavage at the S1/S2 site to enable fusion of the viral envelope with the host cell membrane. Thus, TMPRSS2 could be a possible biological target in therapies and vaccines strategies and the entry 
of SARS-CoV-2 into the host cells could be prevented by TMPRSS2 inhibitor (camostat mesylate). In fact, TMPRS2 inhibitor (camostat mesylate) is already in use in Japan for treatment of pancreatitis which proposes its possible benefit in treating Covid-19 cases(23).

\section{Immune response to SARS- CoV-2:}

The main aim of both innate and adaptive immune responses against viral infections, in general, is to block the viral infection and eliminate the infected cells (Fig. 1). Type I interferons secreted during innate immunity and neutralizing antibodies produced through adaptive immune system could prevent the viral infection. However, if the cells got already infected, then it is the role of the natural killer (NK) cells as a part of the innate immune system and the cytotoxic CD8 T cells of the adaptive immune system to eliminate them $(25)$.

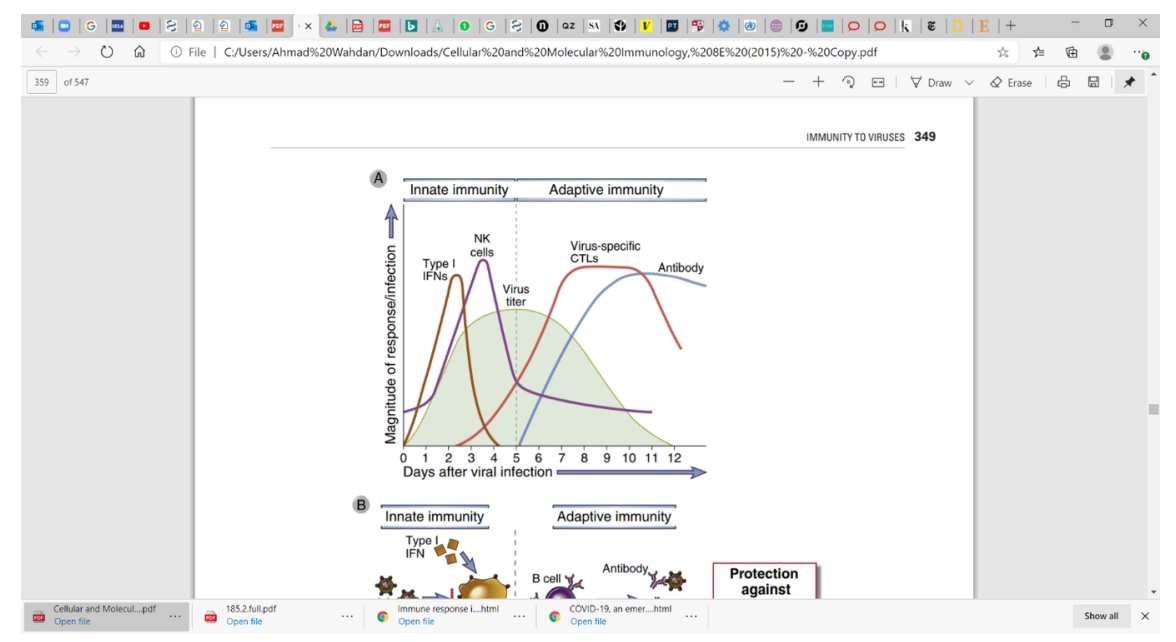

Fig. 1: Kinetics of innate and adaptive immune responses to a virus infection, copied from: (25).

In specific, SARS-CoV-2 infection involves the activation of both innate and adaptive immune systems to clear the infection(26). However, the exaggerated proinflammatory cytokines production has been proposed to cause pathologic condition in lungs characterized by occurrence of respiratory distress which could be followed by pulmonary failure with or without multi organ failure(11).

In the same context, marked increase in proinflammatory cytokines and chemokines such as, Il-1 $\beta$, Il-2, Il-6, Il-8, Il-17 and TNF alpha was also noticed in COVID-19 cases(27). Moreover, elevated levels of neutrophil lymphocyte ratio (NLR) and proinflammatory cytokines and chemokines in COVID-19 patients was correlated with more severe form of the disease and worse prognosis hypothesizing the relation between the inflammatory responses in patients and the immunopathologic nature of the disease(28).

Another study has shown that SARS-CoV-2 patients with severe complications had increased concentrations of inflammatory markers such as high-sensitivity C-reactive protein (Hs-CRP)(29) which is a member of the pentraxin family and an important acute phase protein that plays a fundamental role in both innate and adaptive immune responses $(30,31)$.

\section{Innate Immunity to SARS-CoV-2:}

The main process by which the innate immune system fights any viral infection is production of type I interferons by the infected cells particularly the plasmacytoid dendritic cells and cytotoxic killing of the viral infected cells by the NK cells $(25)$.

Production of interferons is initiated by recognizing the viral nucleic acid by the pattern recognition receptors (PRRs) such as endosomal Toll like receptors (TLRs) and retinoic acid-inducible gene (RIG) like receptors. 
After ligand-receptor binding, PRRs stimulate certain adaptor proteins which, in turn leads to the activation of critical down-stream transcription factors, including the interferon regulatory factor (IRF) transcription factor which initiate interferon gene transcription leading to production of interferons. Type I interferons acts by suppressing the viral replication in infected and neighboring cells. Moreover, PRRs activate other signaling pathways such as NF- $\varkappa \mathrm{B}$, and AP-1, leading to secretion of many other cytokines and chemokines(32).

The produced chemokines serve in recruiting cells of innate immunity as neutrophils, monocytes, NK cells and dendritic cells which in turn help in producing more chemokines like MIG, IP-10, and MCP-1 which play important role in attracting lymphocytes and initiating the adaptive immune response(33).

The early immune response initiated by SARS-CoV-2 in comparison to other coronaviruses infections was monitored by several studies. For example, a recent in vitro study reported that both SARS and SARS$\mathrm{CoV}-2$ have equal ability to infect type I and type II pneumocytes and alveolar macrophages with better capability of intracellular replication for SARS-CoV-2 over SARS. However, SARS-CoV-2 was not able to initiate the production of type I, II and III interferons, in addition it had less effective production of other cytokines when compared to SARS immune response at the same early stage of infection. Only 5 cytokines (IL-6, MCP1, CXCL1, CXCL5, and CXCL10/IP10) were expressed by SARS-CoV-2 infection while all the 11 cytokines measured in this study were produced through SARS immune response (34).

Moreover, it was shown that SARS-CoV-2 is associated with less interferons production and increased proinflammatory cytokines release including IL-1B, IL-6, TNF, and IL1RA in a study that investigated the immune response of SARS-CoV-2 in relation to other respiratory viruses such as SARS, MERS, respiratory syncytial virus (RSV), parainfluenza virus 3 (HPIV3), and influenza A virus (IAV). The study involved respiratory cell lines infection, in vivo infection of ferrets as well as lung samples obtained from dead COVID-19 cases(35).

These findings hypothesize that SARS-CoV-2 has an altered immune response compared to the other coronaviruses in term of more capability of intracellular replication in lungs, increased activation of innate immunity associated with higher levels of proinflammatory cytokines as well as high evasion mechanisms abilities that allow it to skip the production of interferons and their antiviral response(16).

On the other side, NK cells play a potential role in fighting viral infection early in the disease before development of adaptive immune response. As an evasion mechanisms of the viruses, the virus infected cells decrease the expression of MHC class I on their surfaces so the immune system could not catch them especially CD8 cytotoxic cells, however, this leads to activation of the NK cells which are inhibited naturally through recognition of $\mathrm{MHC}$ class I on the target cells enabling NK cells to exert their cytotoxic actions against the infected cells and hence eradication of the viral infection(25).

\section{Signaling pathways activated by SARS-CoV-2:}

Knowing the intracellular molecules involved in activation of host immune response may help targeting them in designing therapeutic and vaccines strategies. This may have better effect than targeting the viral peptides themselves which are liable for viral mutations and evasion mechanisms(36)

Since there are many similarities between SARS-CoV-2 and SARS in structure and mode of infection, it is postulated that they share innate immunity methods of signaling pathways activation. Following the attachment of SARS-CoV-2 S protein to ACE2 receptors expressed on the host cells, the viral RNA is recognized through TLR 3, 7 and 8 and the cytosolic RNA receptors ; RIG-I (37).This recognition especially through TLR3, 7 and 8 initiates signaling pathways activation in monocytes such as IRF3 (IFN regulatory factor-3), nuclear factor $\chi \mathrm{B}(\mathrm{NF}-\varkappa \mathrm{B})$, JAK (Janus kinase)/STAT (signal transducer and activator of transcription) leading to Interferon type I and other cytokines production which in turn lead to differentiation of $\mathrm{T}$ cells towards CD4 T helper cells(38).

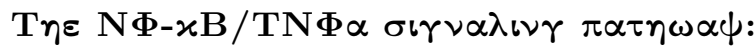

Nuclear factor Kappa Beta $(\mathrm{NF}-\varkappa \mathrm{B})$ is an important transcription factor which plays a significant role in regulating innate and adaptive immune responses. Various pathogens stimulate nuclear translocation of 
NF- $x \mathrm{~B}$ which exists normally in the cytoplasm of cells (39). It, then, initiates the expression of genes whose products are necessary for the inflammatory response such as cytokines and chemokines (40). Although this activation is essential for an optimum immune response, it has been suggested to lead to exaggerated inflammatory response leading to lung injury and respiratory distress caused by respiratory viruses such as SARS (41). Furthermore, NF- $x$ B activation has been implicated in enormous production of IL- 6 and TNF $\alpha$ cytokines in murine macrophages after exposure to recombinant SARS S protein. This was postulated to be due SARS S protein related degradation of $\mathrm{I} \chi \mathrm{B} \alpha$, a normal inhibitor of $\mathrm{NF}-\chi \mathrm{B}$, leading to augmented activation of NF- $x \mathrm{~B}$ signaling pathway (42).

Another study confirms these findings; they found that certain therapies which are able to suppress NF$x \mathrm{~B}$ signaling pathway such as caffeic acid phenethyl ester and parthenolide led to decreased inflammatory process by inhibiting the expression of genes encoding inflammatory cytokines and chemokines as TNF $\alpha$, CXCL2, and MCP-1 in the lungs of mice having SARS infection. This in turn helped in preventing disease progression in those mice and decreased their mortality rates after the infection(41) .

Similarly, it was reported that infection with SARS in macaques has led to increased translocation of NF$x \mathrm{~B}$ secondary to its activation especially in old ones more than the younger macaques leading to a strong inflammatory viral response(43).

All these data suggest that suppression of NF- $\varkappa$ B could be an efficient way to escape the undesirable inflammatory process caused by SARS, however, designing therapies that aim to target this molecule specifically may be problematic and could instead affect the normal innate immunity process leading to exacerbation of infections. In addition, many viruses have the ability to successfully block this signaling pathway leading to in-effectivity of such therapy and highlights the hope of targeting its inflammatory products instead such as $\mathrm{TNF} \alpha$ (44). Furthermore, Anti-TNF $\alpha$ biological treatments such as infliximab and adalimumab have been tried in treating a variety of autoimmune diseases such rheumatoid arthritis and psoriasis with a reasonable success rate which favors targeting this cytokine specifically among the other inflammatory cytokines which are involved in the cytokine storm (45). In fact, patients with active rheumatoid arthritis who were treated with such therapies had also diminished levels of other inflammatory cytokines including IL-6 and IL-1 leading to fast amelioration of their inflammatory conditions. Indeed, when an anti-TNF $\alpha$ is administrated in patients with active rheumatoid arthritis, it has been demonstrated to induce a rapid decrease of a broad spectrum of cytokines (e.g. IL-6 and IL-1), as well as of others acute-phase related proteins and vascular permeability factor $(46)$

Based on these data and on the high similarity between SARS-CoV 2 and SARS, monoclonal antibodies against TNF $\alpha$ were hypothesized to suppress the cytokine storm occurring in COVID-19 patients and decrease its possible consequences. A clinical trial study using Adalimumab as TNF $\alpha$-inhibitor has been started in Chinese COVID-19 patients to investigate its efficacy and safety as well (8).

Moreover, it was found that TNF $\alpha$-converting enzyme (TACE)-mediated shedding of ACE2 which is required for virus internalization into the host cells is enhanced by SARS S protein. This means that monoclonal antibodies against TNF $\alpha$ could exert their therapeutic effects through double hypotheses: prevention of viral entry and weakening of the inflammatory process and cytokine storm (47).

\section{The IL-6/JAK/STAT signaling pathway:}

IL-6 was found to be elevated significantly following SARS-CoV 2 infection where it was postulated to participate strongly in the cytokine storm in infected patients (48). IL-6 interacts with its receptors expressed on the immune cells such as glycoprotein 130 (gp 130) receptor and membrane bound IL-6 receptor as well as soluble receptor for gp130 leading to activation of the JAK/STAT signaling pathway (49) . Actually, there is bidirectional relationship between both IL-6 and JAK/STAT signaling pathway meaning that they could stimulate each other as activation of JAK/STAT signaling leads to more IL-6 secretion and vice-versa(50).

Many cell types are known to produce IL-6 such as macrophages, endothelial and smooth muscle cells and once produced, it stimulates the production of other cytokines especially MCP-1 which induces atherogene- 
sis(51), increased expression of adhesion molecules(52) and proliferation of vascular smooth muscle cells (53). This may consequently explain the cardiovascular complications occurring in COVID-19 patients where high levels of IL-6 are detected (54).

The production of IL-6 is seen to be caused by angiotensin II, which is locally generated by inflamed vessels to bind to its receptor; angiotensin II receptor type 1 (AT1 receptor) leading to activation of JAK / STAT signaling. The augmented production of angiotensin II promotes more IL-6 secretion in AT1/JAK/STATdependent way, thus entering in a vicious circle of inflammatory response (55).

Remarkably, it was found that SARS S protein has an important role in decreasing the expression of ACE2 with a subsequent increase of angiotensin II (56). Similarly, it was postulated that SARS-CoV-2 could exert same actions and decrease ACE2 receptors expression leading to increased accumulation of angiotensin II and hence increased IL-6 secretion leading to cardiovascular complications and pulmonary damage (Fig. 2) (8). In addition, this inflammatory pathway has been implicated in the activation of NF- $x \mathrm{~B}$ and ADAM pathways. Particularly, ADAM17 causes ACE2 cleavage thus inactivating it, and increasing angiotensin II, accordingly leading to hypertension and other cardiovascular pathologies (57).

It was demonstrated that the metalloprotease ADAM17 transforms the membrane form of IL-6 receptor $\alpha$ (IL-6R $\alpha$ ) to its soluble form (sIL-6R $\alpha$ ) with the subsequent activation of STAT3 which in turn activates $\mathrm{NF}-x \mathrm{~B}$ signaling. Therefore, SARS-CoV-2 could lead to activation of both NF- $\varkappa \mathrm{B}$ and STAT3 pathways promoting the enhanced production of IL- 6 which is in turn implicated in more activation of NF- $x \mathrm{~B}$ by STAT3 leading to a hyper-inflammatory response and may proceed to development of autoimmune diseases (58). It was proposed that the amplified production of IL-6 induces the secretion of many other inflammatory cytokines and chemokines leading to migration of lymphocytes and leucocytes to the site of inflammation and maintaining the IL-6 mediated inflammatory response at its highest level(Fig. 2) (59).

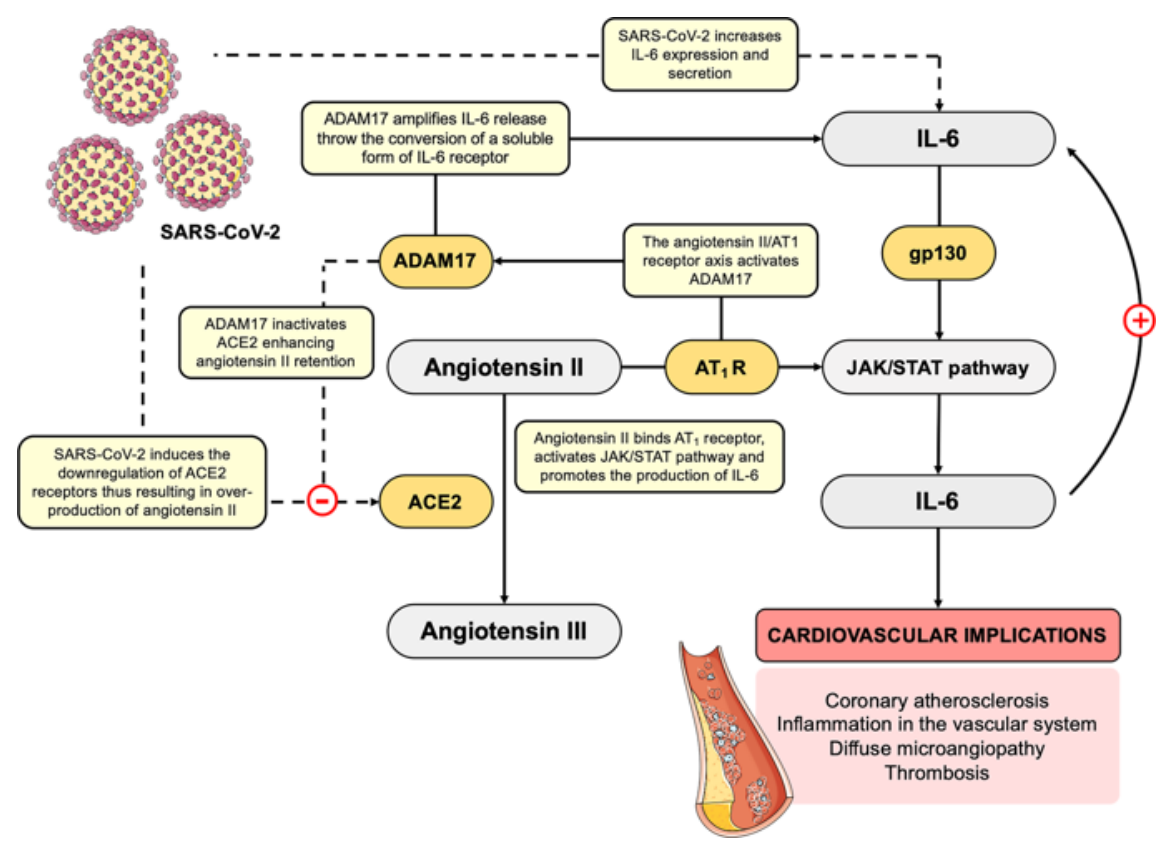

Fig. 2: Hypothetical mechanism by SARS-CoV-2 in establishing an inflammatory feedback loop between IL-6 and angiotensin II, copied from: (8)

\section{Sphingosine-1-phosphate receptor 1 pathway:}

Sphingosine-1-phosphate (S1P) 1 is a key signaling pathway that plays a role in regulating the inflammatory process; it involves lymphoid cells recruitment, vascular permeability and production of cytokines and 
chemokines. It exerts its functions after binding to its receptors; five G-protein-coupled receptors (S1PRs1-5) which exist in different types of cells (60).

The activation of S1P1 receptor which is usually bound to a G inhibitory protein and widely expressed on many types of cells leads to stimulation of Ras/ERK signaling pathway (61). Interestingly, the S1P1 receptor signaling was found to limit the immunopathological injury caused by both innate and adaptive responses, hence suppressing the cytokine storm formation following Influenza viral infection mainly through diminished production of IFN- $\alpha$, CCL2, IL-6, TNF $\alpha$, and IFN- $\gamma$ which helped in decreasing the mortality rates in the infected mice (36). Similarly, in another study done later, it was found that stimulation of S1P1 has led to blockage of cytokines secretion and inhibited migration of inflammatory cells to the lungs of H1N1 influenza infected mice. It was demonstrated that these actions were exerted through reduction of cytokine storm independently of TLR3 and TLR7 signaling pathways but rather through targeting MyD88 (myeloid differentiation primary response gene 88 )/TRIF (TIR-domain-containing adapter-inducing IFN- $\beta$ ) signaling which are main players in the NF- $x \mathrm{~B}$ pathway (62).

\section{Cytokine storm:}

It is well observed clinically that one of the main causes of deterioration of patients' clinical conditions is the significant increase of proinflammatory cytokines levels in their sera suggesting the importance of this immune defense mechanism in the pathological processes of this disease(27). This huge increase in cytokines levels or what is known clinically with cytokine storm, could lead to serious pathologic findings including increased vascular permeability, increased blood viscosity, deteriorated pulmonary functions which could be associated with multiple organ failure and death(63).

A study which compared COVID-19 patients who were admitted to ICU units with clinically stable patients and normal controls found that there was noticeable increase in serum levels of certain cytokines including IL-1 $\beta$, IL-1ra, IL-7, IL-8, IL-9, IL-10, basic FGF, G-CSF, GM-CSF, IFN- $\gamma$, IP-10, MCP-1, MIP-1 $\alpha$, MIP-1 $\beta$, PDGF, TNF $\alpha$, and VEGF in ICU and stable patients in relation to the third group. In specific, IL-2, IL-7, IL-10, G-CSF, IP-10, MCP-1, MIP-1 $\alpha$, and TNF $\alpha$ were even higher in those admitted to ICU compared with the clinically stable patients highlighting the role of the cytokine storm in worsening the patients' clinical conditions(64). Another study showed similar findings suggesting the relation between the increase in proinflammatory cytokines levels and the occurrence of serious lung pathology (65).

The cytokine storm has been proposed to be in part due to abnormal GIT microbiota features which have normally important role in maintaining a balanced host immune response. In a study which involved 366 study subjects, it was found a significant correlation between microbiota disturbance and uncontrolled production of inflammatory cytokines suggesting a relation between COVID-19 cytokine storm and microbiota patterns. Examples of these microbiota are Bacteroides genus, Streptococcus genus and Clostridiales which had negative correlation with the measured proinflammatory cytokines while Ruminococcus genus, Blautia genus and Lactobacillus genus had positive correlation (66).

\section{Adaptive Immunity to SARS-CoV-2:}

Adaptive immune response against viruses in general, is directed mainly by humoral immunity which secretes neutralizing antibodies to block the binding of the viruses to their receptors on the target host cells and hence prevent their internalization inside these cells. The other arm of the adaptive immunity is the cell mediated $\mathrm{T}$ cell response which is concerned with cytotoxic killing of the virus infected cells which leads to eradication of the infection (Fig 3). The antibodies produced by T-dependent germinal center interactions are high affinity antibodies making them more efficient in neutralizing the viruses in their extracellular stage; before their entry into the host cells or during virus budding to infect neighboring cells or after death of the infected cells. These antibodies neutralize the viral infection by attaching to the viral envelope or capsid antigens and then prevent the virus binding and internalization to the host cells, consequently, the cycle of viral infection and spread to the near cells is broken down. Among the neutralizing antibodies, the IgA immunoglobulins are the most effective for blocking the viral infection in respiratory and intestinal systems. Furthermore, these antibodies may also opsonize the viruses and initiates their phagocytosis. In addition, 
complement system may help the humoral immunity by opsonizing the viruses-antibodies complexes and promoting their phagocytosis as well as formation of membrane attack complexes (MAC) in the envelope of certain viruses leading to their lysis $\operatorname{directly}(25)$.

Once the virus succeeds in entering the cell, then, it is not accessible anymore to the neutralizing antibodies and they have no effect on the viral infection at this stage. Then it is the role of the cell mediated immunity to interfere, mainly the CD8 $\mathrm{T}$ cells which recognize the virus antigens expressed on the groove of MHC class I of the infected cells. This leads to the activation of CD 8 cytotoxic T lymphocytes (CTLs), usually with the help of $\mathrm{T}$ helper lymphocytes cytokines, and the costimulatory molecules expressed on the surface of infected cells in order to reach the full activation and clonal expansion process. The effector CTLs exert their cytotoxic actions against the viral infected cells leading to their killing and elimination of the infection. They may also eradicate the viral infecting cells by other ways such as activation of nucleases inside the target cells leading to degradation of the viral genome (25).

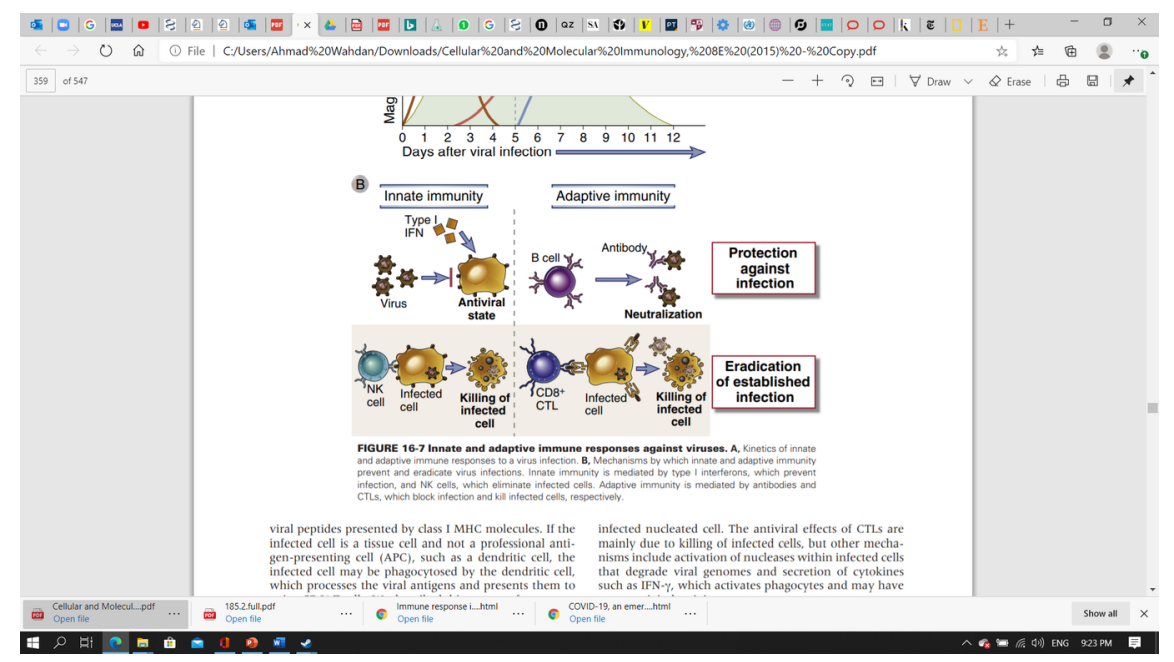

Fig. 3: Mechanisms by which innate and adaptive immunity prevent and eradicate virus infections, copied from:(25).

It is reported that SARS-CoV-2 affect largely total lymphocytic count especially CD3, CD4 and CD8 cells which were found to be much lower in patients with severe clinical conditions and mortalities in relation to cured ones(29).

In fact, lymphocytopenia associated with change in the total leucocytic count is seen constantly in Covid-19 patients suggesting the disease severity and prognosis(19).

Moreover, in severe infections, flowcytometric analysis showed a significant decrease in all components of total leucocytic count including peripheral B lymphocytes, CD4 T helper lymphocytes, CD8 cytotoxic lymphocytes, NK cells, monocytes, eosinophils and basophils(67).

Another study done in Wuhan on 452 SARS-CoV-2 patients showed decrease in total count of T lymphocytes including both helper $\mathrm{T}$ cells, regulatory $\mathrm{T}$ cells ( $\mathrm{T}$ reg) and memory $\mathrm{T}$ cells, however naïve $\mathrm{T}$ cells count was reported to be elevated(28). Both naïve $\mathrm{T}$ cells and memory $\mathrm{T}$ cells are necessary to keep the immune response well-coordinated and effective as Naïve $\mathrm{T}$ cells are responsible of fighting new infections while memory $\mathrm{T}$ cells induce the antigen specific adaptive immunity. If there is an increase in naïve $\mathrm{T}$ cells in relation to regulatory $\mathrm{T}$ cells, then this favors an exaggerated production of pro-inflammatory cytokines leading to a hyperinflammatory response whereas if there is a decrease in the memory $\mathrm{T}$ cells count, this in 
turn could lead to reinfection with SARS-CoV-2 as these cells are in charge of defensing the body against the same infection in case of re-exposure(19). One of the explanations of decreased lymphocytic count in these patients is the direct infection of lymphocytes by SARS-CoV-2 leading to their lysis(68).

Regarding humoral immune system, Wen et al. showed marked decrease in naïve B lymphocytes count with significant increase of plasma cells count in the peripheral blood mononuclear cells of COVID-19 patients during their recovery period. Furthermore, some modifications in B cell receptors were noticed(69). As B cells play a significant role in controlling viral infections, monitoring the seroconversion patterns in COVID19 patients is crucial for assessing their conditions clinically. It was reported that $96.8 \%$ of patients had seroconversion of $\operatorname{IgG}$ or IgM within 20 days from the onset of symptoms followed by a plateau phase for 6 days later. All the studied subjects had virus specific IgG antibodies around 17-19 days since the first symptoms appeared while only $94.1 \%$ of them achieved virus specific IgM antibodies around 20-22 days after the start of symptoms(70).

\section{Vaccines overview:}

Recently, there have been several attempts to create vaccines against human Corona virus infections, however, all were limited due to their wide diversity of sequences(71). Several vaccines and immunotherapies have been tried during the latest viral epidemics such as Zika, Ebola and the previous CoVs family infections. Most of these trials have been investigated firmly to assess their applicability and usefulness in preventing the current pandemic (72).

Most of the current $\mathrm{CoV}$ vaccines attempts are targeting the $\mathrm{S}$ protein of the virus as it is the principal promotor of antibodies development and T-cell responses making it the perfect candidate in vaccines development strategies. Examples of these vaccines are involving the full length $\mathrm{S}$ protein or other appropriate parts of it or S1 receptor binding domain or virus like particles (VLP), viral vectors or DNA (71), (73), (74)and (75).

The most efficient vaccine should enhance both the production of blocking antibodies that target the S1 subunit receptor binding domain to block the binding of the $\mathrm{S} 1$ protein of the virus to its receptor, in addition to blocking the viral RNA uncoating. Chen et al., has demonstrated that the C-terminal domain of the S1 subunit of porcine Deltacoronavirus conatins the immunodominant region that evolves the strongest blocking effect(76). Furthermore, because of RBD capability to trigger the formation of neutralizing antibodies, both recombinant peptides containing RBD and recombinant vectors encoding RBD may be promising for the production of successful SARS-CoV vaccines(74).

Kim et al has shown that the nasal administration of recombinant adenovirus-based vaccines that express MERS Spike protein into mice, enhances the production of $\operatorname{IgG}$ and secretory $\operatorname{IgA}$ antibodies as well as inducing the activation of $\mathrm{T}$ lymphocytes and development of memory cells which reside mainly in lungs giving those mice life-long immune response responses(77).

Moreover, a study which compared the effect of rabies virus as a viral vector against Gram-positive enhancer matrix (GEM) as a bacterial vector; both of them expressing MERS Spike protein; they found that the viral vector vaccine gave the mice markedly stronger cell mediated immune response and faster humoral immunity(78). Additionally, knowing that there are much similarities between SARS and MERS, the applicability of designing one vaccine working against all $\mathrm{CoV}$ family viruses was investigated and they found that there is possible cross-reactivity among $\mathrm{CoVs}(79)$.

Also, since SARS-CoV-2 and SARS exhibit antigenic similarity, vaccines developed against SARS could be cross-reactive against SARS-CoV-2 (80). However, when the sequences of the full-length S protein of SARSCoV-2 was compared with that of SARS, they found that the most variable regions exist in the S1 subunit of spike protein which is normally the main target of most developed vaccine(81) which may assume the difficulty of designing one common efficient vaccine for both viruses (82).

The nucleocapsid $(\mathrm{N})$ protein and the possible B cell epitopes of MERS E protein have been recommended as feasible targets that could initiate cell mediated and humoral immune interactions(83). In addition, reverse 
genetic approaches were applied in live-attenuated vaccines to deactivate the exonuclease effects of nonstructural protein 14 (nsp14) or to eliminate the envelope protein in SARS (71). Avian infectious bronchitis virus (IBV) is a chicken Corona virus and it was suggested by Bijlenga that strain $\mathrm{H}$ of avian live virus IBV vaccine might be helpful in protecting against SARS (84). Since this vaccine is depending mainly on the production of neutralizing antibodies, so it may be suggested as another effective choice for protection against SARS-CoV-2 after assessing its efficacy in monkeys(85).

Rocky Mountain Laboratories are cooperating with Oxford University to grow an adenovirus vector vaccine against SARS-CoV-2 to be tried in chimpanzees first. In addition, another study is investigating clinical trials for a new vaccine expressing SARS-CoV-2 S protein in the mRNA vaccine platform technology (86). Lately, the Coalition for Epidemic Preparedness Innovations (CEPI) declared the launch of three plans designed to produce SARS-CoV-2 vaccines using already existing vaccines' platforms. These platform work through the synthesis of viral surface proteins which bind to the host cell membrane and clamp the cells into shape. This could enhance better and faster detection of viral antigens by the host immunity(87).

\section{Passive Immunization:}

Observing that infected individuals with SARS infection have efficient neutralizing antibodies after their recovery, it was postulated that the use of monoclonal antibodies may be efficient in controlling CoV infections after the exposure to the virus(73).

A clinical trial study involving the administration of a group of monoclonal antibodies directed against six specific epitopes in MERS S protein which are responsible for receptor binding and membrane fusion has started(88). Similarly, targeting many S protein epitopes may be a promising strategy to augment the humoral immune response against CoVs infections. The cross-reactivity of monoclonal antibodies directed against SARS RBD is significantly based on the similarity among RBDs of $\mathrm{CoVs}(89)$.

These cross-reacting SARS RBD-specific antibodies can be tested for effectiveness in SARS-CoV-2 patients. Hence, comparative studies are needed to compare receptor binding domains of SARS-CoV-2 with those of SARS in order to determine the appropriate antibodies to be investigated clinically $(90)$.

The development of totally human antibodies as human single-chain antibodies or humanized-nanobodies could be possible through technology, these antibodies (transbodies) could traverse the host cell membrane to interrupt the viral replication process through binding to one or more of the viral proteins. Examples of these transbodies are those directed against influenza, hepatitis C virus(HCV), Ebola, and Dengue viruses(91). Therefore, it could be a good option in treating COVID-19 patients with transbodies directed against the SARS-CoV-2 intracellular peptides as papain-like proteases (PLpro), cysteine-like protease (3CLpro) or any other non-structural proteins to inhibit the viral replication machinery safely (92).

\section{Animal Models Used in Vaccine development:}

Unfortunately, adequate animal models for assessing Coronaviruses vaccines are not available easily rendering the vaccine production cycle really difficult. Succeeding in developing an appropriate animal model which could imitate the clinical condition in humans would be an effective tool to explore the pathophysiology of the disease and help to evaluate the suitable vaccines and treatments with the minor possible harmful effects. In fact, different types of animals have been used to assess SARS, MERS and SARS-CoV-2 infections. Examples of these animals are mice, guinea pigs, hamsters, rabbits and rhesus macaques (93).

Several attempts were done to develop suitable animal models for SARS-CoV, however, the specificity of the virus to ACE2 was a significant obstacle. Then, Yang et al., succeeded in developing an appropriate transgenic mouse model through the introduction of hACE2 gene into the mouse genome(94). As for MERS, the initial animal model used for development of its vaccine was rhesus macaques. The animal models showed clinical symptoms similar to those occurring in humans such as pyrexia, cough and decreased appetite(95). In addition, other animal models were used for MERS including the common marmoset where the clinical condition progressed to fatal pneumonia. Fortunately, antibodies production as well as activated cell mediated immune response could be identified in these animals after exposure to MERS vaccine (96). Furthermore, 
golden Syrian hamster was used as animal model to evaluate the vaccine development process against several strains of SARS to assess the virus pathophysiology as well as the vaccine effectiveness and safety(97).

Incapability of MERS to replicate in the lungs of mice, hamsters or ferrets made these animals inapplicable animal models for it. These animals are naturally susceptible to SARS but resist MERS infection. However, Zhou et al., have been succeeded in modifying them genetically to be able for MERS infection and replication(98). Such efforts for genetic modification of these small animals including mice and rabbits to enable them to be susceptible to such viral infections, though time consuming, but are favored as these models are more cost-effective and easier to be manipulated when compared with larger animals (99). More studies are required in order to identify the most appropriate animal models for the novel SARS-CoV-2. This will involve determining the degree of specificity of the virus to its receptors on host cells as well as investigating its pathophysiology and specific immune response.

\section{Strategies of developing specific SARS-CoV-2 vaccine:}

Some mRNA vaccines have been developed for SARS-CoV-2 (table 1.), they encode stable form of S protein before its fusion to the host cell membrane and depend mainly on a recent genetic technique which does not involve viral culture in the laboratory but in the human body instead. This method involves mRNA fragments that encode the viral proteins which are then injected into the body, subsequently, the viral proteins are presented by the antigen presenting cells to be recognized by $\mathrm{T}$ and $\mathrm{B}$ lymphocytes to start the activation of the host antiviral immune response(7). Currently, there are many candidate mRNA vaccines that have been approved by WHO. Most of them are still in the pre-clinical stage of study except an LNP-encapsulated mRNA vaccine developed by Moderna company and is currently in the clinical evaluation stage, phase I (100).

DNA vaccines reflect the new evolutionary path of vaccine production. Genetic manipulation is used to generate the vaccinations produced through recombinant DNA processing. Basically, the DNA which encodes the target protein is inserted into the appropriate cell line or microorganism by a plasmid or viral vector where the DNA is then converted to a protein. Afterwards, the product is extracted by purification technique(101). One of the advantages of DNA vaccines is that it is easy to manufacture such plasmids in big amounts in addition to the long-life immunity they could provide (102).

AZD1222 is a recent DNA vaccine under trial (formerly known as ChAdOx1 nCoV-19) that is using adenovirus vector and targeting SARS-COV-2 S protein resulting in generation of humoral immune response with production of immunoglobulins against the virus. Five hundred and 10 volunteers aged between 18 and 55 years old were enrolled in this single-blind randomized clinical trial study which generated an acceptable safety profile and promising immunogenicity (103).

Preclinical investigations have been done in animal models to test the results and efficacy of another DNA vaccine and has shown good primary outcomes, then it was proceeded to enter human clinical trial, phase I. The vaccine with the name INO-4800 vaccine is involving 40 healthy individuals who are receiving, each, 2 doses of the vaccine with 4 weeks interval in between, then their antibody responses are assessed(104). Other many candidate DNA vaccine are approved by WHO but they are still in the preclinical phase of study.

Similarly, eleven SARS-CoV-2 protein subunit candidate vaccines are approved by WHO, all of them are in the preclinical phase. Examples include capsid-like particle AdaptVac, Drosophila S2 insect cell expression system VLPs and peptide antigens formulated in lipid nanoparticle formulation (100). Protein Subunit vaccines include some epitopes of the virus usually produced through recombinant DNA techniques or viral culture(105). One advantage of this type of vaccines is the relatively fewer number of antigens, hence lower chance of potential side effects. However, this low number of antigenic epitopes could elicit weaker immune response but this disadvantage is treated by conjugating such epitopes with adjuvant proteins to bypass this weakness(106).

Additionally, many replicating and non-replicating viral vector candidate vaccine are being tested for efficacy and safety. Replicating viral vectors such as measles, influenza vector expressing RBD and horsepox vector 
expressing $\mathrm{S}$ protein are in the preclinical experiments phase while non replicating viral vectors such as adenovirus type 5 vector is proceeding to clinical trial phase I and II with favorable initial results in the preclinical phase (100).

Another advanced strategy is the production of vaccines that are formed of virus like particles (VLPs) such as parts of the viral surface proteins. This is a complex procedure that involves processing these particles into more immunogenic proteins that could initiate the host antibody and cell mediated immunity(107). VLP vaccine expressing viral RBD as well as plant derived VLP are being tested pre-clinically and approved by $\mathrm{WHO}(100)$.

Inactivated viruses' vaccines work through including the whole virus which has been deactivated either chemically or physically. These vaccines are more stable compared to other types of vaccines as they are usually maintained in powder form, but unfortunately less effective and more expensive due to its complicated production machinery(108). Three inactivated virus candidate vaccines are in the clinical human trial stage phase III and are approved by $\mathrm{WHO}(100)$.

Table 1. Summary of SARS-CoV-2 candidate vaccines proceeding to phase 3 of human clinical trials approved by WHO, August 13, 2020(109)

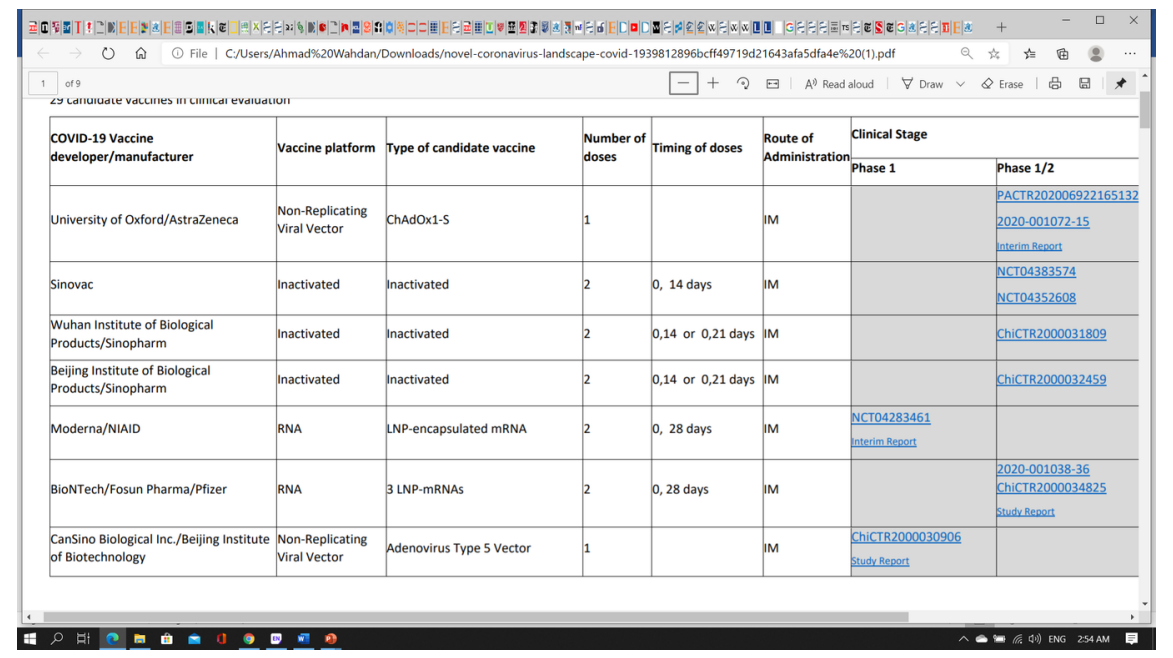

\section{Summary and Future perspectives:}

The novel corona virus, SARS-CoV-2, is one of the most challenging crises that faced the whole world since the 1918 Influenza outbreak unveiling the hidden weaknesses of the health care systems globally and urging the need for efficient and safe vaccines and therapies development. Luckily, vaccine research has advanced dramatically over the last period, with the creation of multiple types of RNA and DNA vaccines, approved viral vector vaccines, recombinant peptides in addition to cell culture based immunotherapies(110). Based on the high similarity between SARS-CoV-2 and SARS, the identification of S protein, present in both viruses and responsible for virus binding to the host cell membrane and its internalization into the cell has been facilitated and proposed as the main target for many vaccines under trials. This will help in quick production of neutralizing antibodies that bind to the S protein and hence prevent the infection process. Nevertheless, although many $\mathrm{S}$ protein targeting vaccines have been developed already aiming to protect against SARS and MERS, most of them did not give the desirable results when tested in animal models or caused severe harmful effects as lung injury or multiorgan failure(111),(112). In addition, it is not well-known whether the infection with this virus involves lifelong immunity nor the possibility of re-infections which urge researchers all over the world to continue their research on this topic in order to explore the exact pathophysiology of the virus and to develop a highly effective vaccine and treatment. 
However, the specific immune signaling pathways stimulated by SARS-CoV-2 are still to be well identified as this may ensure a great hope in revealing the reliable and significant biological markers to be targeted in vaccines and immunotherapies in order to block the cytokine storm occurring in most of the severe cases. Moreover, since it is known that the innate immunity stimulates many signaling pathways, it would be more promising to target various signaling pathways simultaneously during the course of treatment which should include a combination of specific cytokine blockers, corticosteroids as well as S1PR1 agonists instead of administering only one drug as this may enhance the chance of recovery especially in advanced cases. Therefore, more studies are needed to evaluate if this combination of drugs could protect the patients against the progression of lung damage and multi organ failure compared with single target drug regime plans.

Finally, all the above-mentioned issues illustrate some of the main holes in our understanding of COVID-19 physiological implications, fundamental immune signaling mechanisms, and effective vaccines development strategies that prospective studies desperately need to tackle.

\section{Conflict of interest}

The author declares no conflict of interest.

\section{Funding}

No sources of funding were used for this work.

\section{References:}

1. Asia Cn. Novel Coronavirus Map 2020 [updated 12/08/2020. Available from: https://infographics.channelnewsasia.com/covid-19/map.html.

2. WHO. WHO Coronavirus Disease (COVID-19) Dashboard 2020 [Available from: https://covid19.who.int/.

3. Lu R, Zhao X, Li J, Niu P, Yang B, Wu H, et al. Genomic characterisation and epidemiology of 2019 novel coronavirus: implications for virus origins and receptor binding. Lancet. 2020;395(10224):565-74.

4. de Wit E, van Doremalen N, Falzarano D, Munster VJ. SARS and MERS: recent insights into emerging coronaviruses. Nat Rev Microbiol. 2016;14(8):523-34.

5. Fauci AS, Lane HC, Redfield RR. Covid-19 - Navigating the Uncharted. N Engl J Med. 2020;382(13):12689 .

6. Vabret N, Britton GJ, Gruber C, Hegde S, Kim J, Kuksin M, et al. Immunology of COVID-19: Current State of the Science. Immunity. 2020;52(6):910-41.

7. Calina D, Docea AO, Petrakis D, Egorov AM, Ishmukhametov AA, Gabibov AG, et al. Towards effective COVID19 vaccines: Updates, perspectives and challenges (Review). Int J Mol Med. 2020;46(1):3-16.

8. Michele Catanzaro FF, Marco Racchi, Emanuela Corsini, Stefano Govoni \& Cristina Lanni. Immune response in COVID-19: addressing a pharmacological challenge by targeting pathways triggered by SARSCoV-2. Signal Transduction and Targeted Therapy. 2020;5(84):1-10.

9. Li H, Wang YM, Xu JY, Cao B. [Potential antiviral therapeutics for 2019 Novel Coronavirus]. Zhonghua Jie He He Hu Xi Za Zhi. 2020;43(3):170-2.

10. Cyranoski D. This scientist hopes to test coronavirus drugs on animals in locked-down Wuhan. Nature. 2020;577(7792):607.

11. Wu F, Zhao S, Yu B, Chen YM, Wang W, Song ZG, et al. Author Correction: A new coronavirus associated with human respiratory disease in China. Nature. 2020;580(7803):E7. 
12. Zhou P, Yang XL, Wang XG, Hu B, Zhang L, Zhang W, et al. A pneumonia outbreak associated with a new coronavirus of probable bat origin. Nature. 2020;579(7798):270-3.

13. Gorbalenya AE, Baker SC, Baric RS, de Groot RJ, Drosten C, Gulyaeva AA, et al. Severe acute respiratory syndrome-related coronavirus: the species and its viruses-a statement of the coronavirus study group. BioRxiv. 2020.

14. WHO. Naming the Coronavirus Disease (COVID-19 and the Virus That Causes it 2020 [Available from: https://www. who.int/emergencies/diseases/novel-coronavirus-2019/technical-guidance/ naming-thecoronavirus-disease-(covid-2019)-and-the-virus-that-causesit.

15. Corman VM, Lienau J, Witzenrath M. [Coronaviruses as the cause of respiratory infections]. Internist (Berl). 2019;60(11):1136-45.

16. Garcia LF. Immune Response, Inflammation, and the Clinical Spectrum of COVID-19. Front Immunol. 2020;11:1441.

17. Mackenzie JS, Smith DW. COVID-19: a novel zoonotic disease caused by a coronavirus from China: what we know and what we don't. Microbiol Aust. 2020:MA20013.

18. Chan JF, Lau SK, To KK, Cheng VC, Woo PC, Yuen KY. Middle East respiratory syndrome coronavirus: another zoonotic betacoronavirus causing SARS-like disease. Clin Microbiol Rev. 2015;28(2):465-522.

19. Zhou L, Liu, K. \& Liu, H. G. Cause analysis and treatment strategies of recurrence' with novel coronavirus pneumonia (covid-19) patients after discharge from hospital. Zhou, L, Liu, K \& Liu, H G Cause analysis and treatment strategies of recurrence' with novel coronavirus pneumonia Chin J Tuberc Respir Dis. 2020;43(4):281-4.

20. Fung TS, Liu DX. Human Coronavirus: Host-Pathogen Interaction. Annu Rev Microbiol. 2019;73:52957.

21. Zou X, Chen K, Zou J, Han P, Hao J, Han Z. Single-cell RNA-seq data analysis on the receptor ACE2 expression reveals the potential risk of different human organs vulnerable to $2019-\mathrm{nCoV}$ infection. Front Med. 2020;14(2):185-92.

22. Wan Y, Shang J, Graham R, Baric RS, Li F. Receptor Recognition by the Novel Coronavirus from Wuhan: an Analysis Based on Decade-Long Structural Studies of SARS Coronavirus. J Virol. 2020;94(7).

23. Hoffmann M, Kleine-Weber H, Schroeder S, Kruger N, Herrler T, Erichsen S, et al. SARS-CoV-2 Cell Entry Depends on ACE2 and TMPRSS2 and Is Blocked by a Clinically Proven Protease Inhibitor. Cell. 2020;181(2):271-80 e8.

24. Letko M, Marzi A, Munster V. Functional assessment of cell entry and receptor usage for SARS-CoV-2 and other lineage B betacoronaviruses. Nat Microbiol. 2020;5(4):562-9.

25. Abul K. Abbas AHL, Shiv Pillai. Cellular and Molecular Immunology: Elsevier saunders; 2015.

26. Control ECfDPa. Immune responses and immunity to SARS-CoV-2 2020 [Available from: https://www.ecdc.europa.eu/en/covid-19/latest-evidence/immune-responses

27. Mehta P, McAuley DF, Brown M, Sanchez E, Tattersall RS, Manson JJ, et al. COVID-19: consider cytokine storm syndromes and immunosuppression. Lancet. 2020;395(10229):1033-4.

28. Chuan Qin LZ, Ziwei Hu, Shuoqi Zhang, Sheng Yang, Yu Tao, MD, Cuihong Xie, Ke Ma, Ke Shang, Wei Wang et al. Dysregulation of Immune Response in Patients With Coronavirus 2019 (COVID-19) in Wuhan, China. Clin Infect Dis. 2020:1-7.

29. Dongze Li YC, Hong Liu, Yu Jia, Fanghui Li, Wei Wang, Jiang Wu, Zhi Wan, Yu Cao, Rui Zeng. Immune dysfunction leads to mortality and organ injury in patients with COVID-19 in China: insights from ERS-COVID-19 study. Signal Transduct Target Ther. 2020;5(62). 
30. Omran A, Maaroof A, Saleh MH, Abdelwahab A. Salivary C-reactive protein, mean platelet volume and neutrophil lymphocyte ratio as diagnostic markers for neonatal sepsis. J Pediatr (Rio J). 2018;94(1):82-7.

31. Omran A, Ali M, Saleh MH, Zekry O. Salivary C-reactive protein and mean platelet volume in diagnosis of late-onset neonatal pneumonia. Clin Respir J. 2018;12(4):1644-50.

32. Hur S. Double-Stranded RNA Sensors and Modulators in Innate Immunity. Annu Rev Immunol. 2019;37:349-75.

33. Perlman SD, A. A. Immunopathogenesis of coronavirus infections:. Nat Rev Immunol. 2005;5:917-27.

34. Chu H, Chan JF, Wang Y, Yuen TT, Chai Y, Hou Y, et al. Comparative replication and immune activation profiles of SARS-CoV-2 and SARS-CoV in human lungs: an ex vivo study with implications for the pathogenesis of COVID-19. Clin Infect Dis. 2020.

35. Blanco-Melo D, Nilsson-Payant BE, Liu WC, Uhl S, Hoagland D, Moller R, et al. Imbalanced Host Response to SARS-CoV-2 Drives Development of COVID-19. Cell. 2020;181(5):1036-45 e9.

36. Teijaro JR, Walsh KB, Cahalan S, Fremgen DM, Roberts E, Scott F, et al. Endothelial cells are central orchestrators of cytokine amplification during influenza virus infection. Cell. 2011;146(6):980-91.

37. de Marcken M, Dhaliwal K, Danielsen AC, Gautron AS, Dominguez-Villar M. TLR7 and TLR8 activate distinct pathways in monocytes during RNA virus infection. Sci Signal. 2019;12(605).

38. Olejnik J, Hume AJ, Muhlberger E. Toll-like receptor 4 in acute viral infection: Too much of a good thing. PLoS Pathog. 2018;14(12):e1007390.

39. Li Q, Verma IM. NF-kappaB regulation in the immune system. Nat Rev Immunol. 2002;2(10):725-34.

40. Hayden MS, West AP, Ghosh S. NF-kappaB and the immune response. Oncogene. 2006;25(51):6758-80.

41. DeDiego ML, Nieto-Torres JL, Regla-Nava JA, Jimenez-Guardeno JM, Fernandez-Delgado R, Fett C, et al. Inhibition of NF-kappaB-mediated inflammation in severe acute respiratory syndrome coronavirusinfected mice increases survival. J Virol. 2014;88(2):913-24.

42. Wang W, Ye L, Ye L, Li B, Gao B, Zeng Y, et al. Up-regulation of IL-6 and TNF-alpha induced by SARS-coronavirus spike protein in murine macrophages via NF-kappaB pathway. Virus Res. 2007;128(12):1-8.

43. Smits SL, de Lang A, van den Brand JM, Leijten LM, van IWF, Eijkemans MJ, et al. Exacerbated innate host response to SARS-CoV in aged non-human primates. PLoS Pathog. 2010;6(2):e1000756.

44. Hiscott J, Nguyen TL, Arguello M, Nakhaei P, Paz S. Manipulation of the nuclear factor-kappaB pathway and the innate immune response by viruses. Oncogene. 2006;25(51):6844-67.

45. Silva LC, Ortigosa LC, Benard G. Anti-TNF-alpha agents in the treatment of immune-mediated inflammatory diseases: mechanisms of action and pitfalls. Immunotherapy. 2010;2(6):817-33.

46. Feldmann M, Maini RN. Anti-TNF alpha therapy of rheumatoid arthritis: what have we learned? Annu Rev Immunol. 2001;19:163-96.

47. Haga S, Yamamoto N, Nakai-Murakami C, Osawa Y, Tokunaga K, Sata T, et al. Modulation of TNFalpha-converting enzyme by the spike protein of SARS-CoV and ACE2 induces TNF-alpha production and facilitates viral entry. Proc Natl Acad Sci U S A. 2008;105(22):7809-14.

48. Puja Mehta DFM, Michael Brown, Emilie Sanchez, Rachel S Tattersall, Jessica J Manson. COVID-19: consider cytokine storm syndromes and immunosuppression. Lancet. 2020;395(10229):1033-4.

49. Zhang C, Wu Z, Li JW, Zhao H, Wang GQ. Cytokine release syndrome in severe COVID-19: interleukin- 6 receptor antagonist tocilizumab may be the key to reduce mortality. Int J Antimicrob Agents. 2020;55(5):105954. 
50. Lee C, Lim HK, Sakong J, Lee YS, Kim JR, Baek SH. Janus kinase-signal transducer and activator of transcription mediates phosphatidic acid-induced interleukin (IL)-1beta and IL-6 production. Mol Pharmacol. 2006;69(3):1041-7.

51. Biswas P, Delfanti F, Bernasconi S, Mengozzi M, Cota M, Polentarutti N, et al. Interleukin-6 induces monocyte chemotactic protein-1 in peripheral blood mononuclear cells and in the U937 cell line. Blood. 1998;91(1):258-65.

52. McLoughlin RM, Hurst SM, Nowell MA, Harris DA, Horiuchi S, Morgan LW, et al. Differential regulation of neutrophil-activating chemokines by IL-6 and its soluble receptor isoforms. J Immunol. 2004;172(9):567683.

53. Xiang S, Dong NG, Liu JP, Wang Y, Shi JW, Wei ZJ, et al. Inhibitory effects of suppressor of cytokine signaling 3 on inflammatory cytokine expression and migration and proliferation of IL-6/IFN-gamma-induced vascular smooth muscle cells. J Huazhong Univ Sci Technolog Med Sci. 2013;33(5):615-22.

54. Qu D, Liu J, Lau CW, Huang Y. IL-6 in diabetes and cardiovascular complications. Br J Pharmacol. 2014;171(15):3595-603.

55. Schieffer B, Luchtefeld M, Braun S, Hilfiker A, Hilfiker-Kleiner D, Drexler H. Role of NAD $(\mathrm{P}) \mathrm{H}$ oxidase in angiotensin II-induced JAK/STAT signaling and cytokine induction. Circ Res. 2000;87(12):1195-201.

56. Glowacka I, Bertram S, Herzog P, Pfefferle S, Steffen I, Muench MO, et al. Differential downregulation of ACE2 by the spike proteins of severe acute respiratory syndrome coronavirus and human coronavirus NL63. J Virol. 2010;84(2):1198-205.

57. Eguchi S, Kawai T, Scalia R, Rizzo V. Understanding Angiotensin II Type 1 Receptor Signaling in Vascular Pathophysiology. Hypertension. 2018;71(5):804-10.

58. Murakami M, Kamimura D, Hirano T. Pleiotropy and Specificity: Insights from the Interleukin 6 Family of Cytokines. Immunity. 2019;50(4):812-31.

59. Hirano T, Murakami M. COVID-19: A New Virus, but a Familiar Receptor and Cytokine Release Syndrome. Immunity. 2020;52(5):731-3.

60. Spiegel S, Milstien S. The outs and the ins of sphingosine-1-phosphate in immunity. Nat Rev Immunol. 2011;11(6):403-15.

61. Bryan AM, Del Poeta M. Sphingosine-1-phosphate receptors and innate immunity. Cell Microbiol. 2018;20(5):e12836.

62. Teijaro JR, Walsh KB, Rice S, Rosen H, Oldstone MB. Mapping the innate signaling cascade essential for cytokine storm during influenza virus infection. Proc Natl Acad Sci U S A. 2014;111(10):3799-804.

63. Zhe Xu LS, Yijin Wang, Jiyuan Zhang, Lei Huang, Chao Zhang, Shuhong Liu, Peng Zhao, Hongxia Liu , Li Zhu, Yanhong Tai , Changqing Bai, Tingting Gao, Jinwen Song, Peng Xia, Jinghui Dong , Jingmin Zhao , Fu-Sheng Wang. Pathological findings of COVID-19 associated with acute respiratory distress syndrome. Lancet Respir Med. 2020;8(4):420-2.

64. Chaolin Huang YW, Xingwang Li, Lili Ren, Jianping Zhao, Yi Hu, Li Zhang, Guohui Fan, Jiuyang Xu, Xiaoying Gu, Zhenshun Cheng, Ting Yu, Jiaan Xia,Yuan Wei and Wenjuan Wu. Clinical features of patients infected with 2019 novel coronavirus in Wuhan, China. The Lancet. 2020;395(10223):497-506.

65. Yingxia Liu CZ, Fengming Huang, Yang Yang, Fuxiang Wang, Jing Yuan, Zheng Zhang, Yuhao Qin, Xiaoyun Li, Dandan Zhao. Elevated plasma levels of selective cytokines in COVID-19 patients reflect viral load and lung injury. National Science Review. 2020;7(6):1003-11.

66. Wanglong Gou YF, Liang Yue, Geng-dong Chen, Xue Cai, Menglei Shuai, Fengzhe Xu, Xiao Yi, Hao Chen, Yi Judy Zhu, Mian-li Xiao, Zengliang Jiang, Zelei Miao, Congmei Xiao, Bo Shen, Xiaomai Wu. Gut 
microbiota may underlie the predisposition of healthy individuals to COVID-19. MedRxiv. 2020.

67. Yaling Shi MT, Xing Chen, Yanxia Liu, Jide Huang, Jingyi Ou, Xilong Deng. Immunopathological characteristics of coronavirus disease 2019 cases in Guangzhou, China. medRxiv. 2020.

68. Li Tan QW, Duanyang Zhang, Jinya Ding, Qianchuan Huang, Yi-Quan Tang, Qiongshu Wang, Hongming Miao. Lymphopenia predicts disease severity of COVID-19: a descriptive and predictive study. Signal Transduct Target Ther. 2020;5(1):33.

69. Wen Wen WS, Hao Tang, Wenqing Le, Xiaopeng Zhang, Yingfeng Zheng, XiuXing Liu, Lihui Xie, Jianmin Li, Jinguo Ye, Xiuliang Cui, Yushan Miao, Depeng Wang, Jiantao Dong, Chuan-Le Xiao, Wei Chen, Hongyang Wang. Immune Cell Profiling of COVID-19 Patients in the Recovery Stage by Single-Cell Sequencing. medRxiv. 2020.

70. Quan-Xin Long B-ZL, Hai-Jun Deng, Gui-Cheng Wu, Kun Deng, Yao-Kai Chen, Pu Liao, Jing-Fu Qiu, Yong Lin, Xue-Fei Cai, De-Qiang Wang, Yuan Hu, Ji-Hua Ren, Ni Tang, Yin-Yin Xu, Li-Hua Yu, Zhan Mo, Fang Gong, Xiao-Li Zhang, Wen-Guang Tian, Li Hu, Xi. Antibody responses to SARS-CoV-2 in patients with COVID-19. Nature Medicine. 2020;26:845-8.

71. Graham RL, Donaldson EF, Baric RS. A decade after SARS: strategies for controlling emerging coronaviruses. Nat Rev Microbiol. 2013;11(12):836-48.

72. Pillaiyar T, Meenakshisundaram S, Manickam M. Recent discovery and development of inhibitors targeting coronaviruses. Drug Discov Today. 2020;25(4):668-88.

73. Yang ZY, Kong WP, Huang Y, Roberts A, Murphy BR, Subbarao K, et al. A DNA vaccine induces SARS coronavirus neutralization and protective immunity in mice. Nature. 2004;428(6982):561-4.

74. Jiang S, He Y, Liu S. SARS vaccine development. Emerg Infect Dis. 2005;11(7):1016-20.

75. Widjaja I, Wang C, van Haperen R, Gutierrez-Alvarez J, van Dieren B, Okba NMA, et al. Towards a solution to MERS: protective human monoclonal antibodies targeting different domains and functions of the MERS-coronavirus spike glycoprotein. Emerg Microbes Infect. 2019;8(1):516-30.

76. Chen R, Fu J, Hu J, Li C, Zhao Y, Qu H, et al. Identification of the immunodominant neutralizing regions in the spike glycoprotein of porcine deltacoronavirus. Virus Res. 2020;276:197834.

77. Kim MH, Kim HJ, Chang J. Superior immune responses induced by intranasal immunization with recombinant adenovirus-based vaccine expressing full-length Spike protein of Middle East respiratory syndrome coronavirus. PLoS One. 2019;14(7):e0220196.

78. Li E, Yan F, Huang P, Chi H, Xu S, Li G, et al. Characterization of the Immune Response of MERS-CoV Vaccine Candidates Derived from Two Different Vectors in Mice. Viruses. 2020;12(1).

79. Liu WJ, Zhao M, Liu K, Xu K, Wong G, Tan W, et al. T-cell immunity of SARS-CoV: Implications for vaccine development against MERS-CoV. Antiviral Res. 2017;137:82-92.

80. Jiang S, Du L, Shi Z. An emerging coronavirus causing pneumonia outbreak in Wuhan, China: calling for developing therapeutic and prophylactic strategies. Emerg Microbes Infect. 2020;9(1):275-7.

81. Yu F, Du L, Ojcius DM, Pan C, Jiang S. Measures for diagnosing and treating infections by a novel coronavirus responsible for a pneumonia outbreak originating in Wuhan, China. Microbes Infect. 2020;22(2):74-9.

82. Morse JS, Lalonde T, Xu S, Liu WR. Learning from the Past: Possible Urgent Prevention and Treatment Options for Severe Acute Respiratory Infections Caused by 2019-nCoV. Chembiochem. 2020;21(5):730-8.

83. Xie Q, He X, Yang F, Liu X, Li Y, Liu Y, et al. Analysis of the Genome Sequence and Prediction of B-Cell Epitopes of the Envelope Protein of Middle East Respiratory Syndrome-Coronavirus. IEEE/ACM Trans Comput Biol Bioinform. 2018;15(4):1344-50. 
84. Bijlenga G. Proposal for vaccination against SARS coronavirus using avian infectious bronchitis virus strain H from The Netherlands. J Infect. 2005;51(3):263-5.

85. Zhang L, Liu Y. Potential interventions for novel coronavirus in China: A systematic review. J Med Virol. 2020;92(5):479-90.

86. NIAID Developing therapeutics and vaccines for coronaviruses https://www.niaid.nih.gov/diseasesconditions/coronaviruses-therapeutics-vaccines2020 [Available from: https://www.niaid.nih.gov/diseasesconditions/coronaviruses-therapeutics-vaccines.

87. CEPI CEPI to fund three programmes to develop vaccines against the novel coronavirus, nCoV20192020 [Available from: https://cepi.net/news_cepi/cepi-to-fund-three-programmes-to-develop-vaccinesagainst-the-novel-coronavirus-ncov-2019/.

88. Goo J, Jeong Y, Park YS, Yang E, Jung DI, Rho S, et al. Characterization of novel monoclonal antibodies against MERS-coronavirus spike protein. Virus Res. 2020;278:197863.

89. Zeng LP, Ge XY, Peng C, Tai W, Jiang S, Du L, et al. Cross-neutralization of SARS coronavirus-specific antibodies against bat SARS-like coronaviruses. Sci China Life Sci. 2017;60(12):1399-402.

90. Cohen J. New coronavirus threat galvanizes scientists. Science. 2020;367(6477):492-3.

91. Seesuay W, Jittavisutthikul S, Sae-Lim N, Sookrung N, Sakolvaree Y, Chaicumpa W. Human transbodies that interfere with the functions of Ebola virus VP35 protein in genome replication and transcription and innate immune antagonism. Emerg Microbes Infect. 2018;7(1):41.

92. Dhama K, Sharun K, Tiwari R, Dadar M, Malik YS, Singh KP, et al. COVID-19, an emerging coronavirus infection: advances and prospects in designing and developing vaccines, immunotherapeutics, and therapeutics. Hum Vaccin Immunother. 2020;16(6):1232-8.

93. Gretebeck LM, Subbarao K. Animal models for SARS and MERS coronaviruses. Curr Opin Virol. 2015;13:123-9.

94. Yang XH, Deng W, Tong Z, Liu YX, Zhang LF, Zhu H, et al. Mice transgenic for human angiotensinconverting enzyme 2 provide a model for SARS coronavirus infection. Comp Med. 2007;57(5):450-9.

95. Munster VJ, de Wit E, Feldmann H. Pneumonia from human coronavirus in a macaque model. N Engl J Med. 2013;368(16):1560-2.

96. Falzarano D, de Wit E, Feldmann F, Rasmussen AL, Okumura A, Peng X, et al. Infection with MERSCoV causes lethal pneumonia in the common marmoset. PLoS Pathog. 2014;10(8):e1004250.

97. Roberts A, Lamirande EW, Vogel L, Jackson JP, Paddock CD, Guarner J, et al. Animal models and vaccines for SARS-CoV infection. Virus Res. 2008;133(1):20-32.

98. Zhou Y, Jiang S, Du L. Prospects for a MERS-CoV spike vaccine. Expert Rev Vaccines. 2018;17(8):67786.

99. Yong CY, Ong HK, Yeap SK, Ho KL, Tan WS. Recent Advances in the Vaccine Development Against Middle East Respiratory Syndrome-Coronavirus. Front Microbiol. 2019;10:1781.

100. (WHO) WHO. DRAFT landscape of COVID-19 candidate vaccines. WHO; Geneva: 2020 2020 [Available from: https://www.who.int/blueprint/priority-diseases/key-action/Novel_Coronavirus_Landscape_nCoV_11April2020.PDF?ua=1urisimplehttps://www.who.int/blueprint/priority-diseases/keyaction/Novel_Coronavirus_Landscape_nCoV_11April2020.PDF?ua=1.

101. Li L, Petrovsky N. Molecular mechanisms for enhanced DNA vaccine immunogenicity. Expert Rev Vaccines. 2016;15(3):313-29. 
102. Ferraro B, Morrow MP, Hutnick NA, Shin TH, Lucke CE, Weiner DB. Clinical applications of DNA vaccines: current progress. Clin Infect Dis. 2011;53(3):296-302.

103. Arena CT. University of Oxford starts enrolment for Covid-19 vaccine trial 2020 [Available from: https://www.clinicaltrialsarena.com/news/oxford-university-covid-19-vaccinetrial/urisimplehttps://www.clinicaltrialsarena.com/news/oxford-university-covid-19-vaccine-trial/

104. Arena CT. Inovio commences Phase I trial of DNA vaccine for Covid-19 2020 [Available from: https://www.clinicaltrialsarena.com/news/inovio-SARS-COV-2-vaccinetrial/urisimplehttps://www.clinicaltrialsarena.com/news/inovio-SARS-COV-2-vaccine-trial/.

105. Zhang N, Tang J, Lu L, Jiang S, Du L. Receptor-binding domain-based subunit vaccines against MERS-CoV. Virus Res. 2015;202:151-9.

106. Lee NH, Lee JA, Park SY, Song CS, Choi IS, Lee JB. A review of vaccine development and research for industry animals in Korea. Clin Exp Vaccine Res. 2012;1(1):18-34.

107. Sarkar B IS, Zohora US and Ullah MA. Virus like particles - A recent advancement in vaccine development. Korean J Microbiol. 2019;55:327-43.

108. Sridhar S, Brokstad KA, Cox RJ. Influenza Vaccination Strategies: Comparing Inactivated and Live Attenuated Influenza Vaccines. Vaccines (Basel). 2015;3(2):373-89.

109. WHO. Draft landscape of COVID-19 candidate vaccines 2020 [Available from: https://www.who.int/publications/m/item/draft-landscape-of-covid-19-candidate-vaccines.

110. Amanat F, Krammer F. SARS-CoV-2 Vaccines: Status Report. Immunity. 2020;52(4):583-9.

111. Bolles M, Deming D, Long K, Agnihothram S, Whitmore A, Ferris M, et al. A double-inactivated severe acute respiratory syndrome coronavirus vaccine provides incomplete protection in mice and induces increased eosinophilic proinflammatory pulmonary response upon challenge. J Virol. 2011;85(23):12201-15.

112. Tseng CT, Sbrana E, Iwata-Yoshikawa N, Newman PC, Garron T, Atmar RL, et al. Immunization with SARS coronavirus vaccines leads to pulmonary immunopathology on challenge with the SARS virus. PLoS One. 2012;7(4):e35421. 